\title{
Research on Sino-Cambodian regional tourism cooperation based on Symbiosis Theory
}

\author{
Yuanhao Guo* \\ School of tourism and hotel management \\ Yunnan University of Finance and Economics \\ Kunming, China \\ 1021882075@qq.com
}

\author{
Yun Liu \\ School of tourism and hotel management \\ Yunnan University of Finance and Economics \\ Kunming, China \\ 1790961097@qq.com
}

\begin{abstract}
Regional tourism cooperation in China and Kampuchea is an important part of China "One Belt One Road" strategy, which is of great significance to the development of tourism between China and Cambodia.In This paper, the author uses the symbiotic theory to analyze the symbiotic mechanism of the Sino-Cambodiann regional tourism cooperation from three aspects: the environmental induction mechanism, the symbiotic dynamic mechanism and the symbiotic damping mechanism. It aims to have a certain theoretical significance to the SinoCambodiann regional tourism cooperation.
\end{abstract}

Keywords—symbiosis theory; China; Kampuchea; regional tourism cooperation

\section{INTRODUCTION}

\section{A. Research Background}

Facing the complex and changeable world economic situation and the opportunities and challenges of regional economic cooperation, China government on March 2015 issued a "push to build Silk Road Economic Belt and $21^{s t}$ Century Maritime Silk Road vision and action" (hereinafter referred to as "One Belt One Road").

In the "One Belt One Road", Chinese government advocates to uphold the principle of "peaceful cooperation, openness and tolerance, mutual learning, mutual benefit and win-win" spirit of the Silk Road and in accordance with the "concept of cooperation, to jointly build and share" principle, through the policy of communication, interoperability of infrastructure, trade flow, capital and people connected", We should promote pragmatic cooperation in an all-round way and create a community of interests, destinies and responsibilities for political mutual trust, economic integration and cultural inclusion.

In December 2015,the Asian infrastructure investment bank, which was founded jointly by 17 countries, was established by China, with the emphasis on infrastructure construction. The purpose of the establishment is to promote regional economic interoperability and economic integration in Asia. "One Belt One Road" strategy will promote along the national including Kampuchea tourism industry to achieve great development, the national development of Kampuchea "four angle strategy" and "One Belt One Road" strategy actively docking, inject

*Corresponding author greater power for the realization of regional economic development.

Kampuchea and China are traditionally friendly neighbors. Since the establishment of the new government of Kampuchea, the high-level interaction between China and Cambodia has been frequent. China and Cambodia have actively maintained the overall situation of CAFTA Relations and the Greater Mekong sub regional economic cooperation. Since China and Cambodia have formed a comprehensive strategic partnership in 2010, the cooperation between the two sides has deepened, especially in the tourism industry, which is the second largest pillar of Kampuchea's economy, and has carried out a series of comprehensive and in-depth cooperation with China's tourism industry.

\section{B. A Review of Related Research}

In CNKI, there are less than 40 searches on the theme of "cooperation between China and Kampuchea", with only 3 articles on the theme of "tourism cooperation between China and Kampuchea". we can see that the research on regional tourism cooperation between China and Cambodia is rather scarce. This paper studies the tourism cooperation between China and Cambodia from the perspective of symbiosis theory. The first people to introduce the concept of symbiosis into tourism was Peter F, Stringer and Philip L Pearce. The first people who made systematic study of symbiotic theory in China was Yuan Chunqing [1], who proposed that "symbiosis is not only a biological and social phenomenon, but also a biological identification mechanism and a social science research method." After that, the study of Symbiosis Theory in tourism field mainly involves five aspects: (1) Scholars who study the connotation of tourism symbiosis include Wu Hong, Zhang Jianhua, Huang Xi Jia [2], etc. (2) The scholars of the symbiotic model of tourism are: Zou Tong, Tang Zhong Xia, and Ben Qian Qian [3]. Their research agrees that the best mode of tourism symbiosis is "Integrated Symbiosis", and the root principle and direction of the development of the symbiotic system are symmetrically mutualistic symbiosis. (3) Scholars who have studied the symbiosis mechanism in tourism field are: Ji Jin Xiong, Li Congyuan, Lv Wanqing [3], etc. (4)Donald Getz and Arvid Vikeny [6] are the main researchers in the field of tourism symbiosis.(5)Scholars who study the symbiotic conditions of tourism include Mao Chang Yi, Niu Wenjun, Gong You Kun[7] and so on. 


\section{The Present Situation OF Regional Tourism DEVELOPMENT AND COOPERATION BETWEEN CHINA AND CAMBODIA}

\section{A. Regional Tourism Development in China and Cambodia}

China is a big country in tourism development. By the end of 2017, China had 52 world heritage sites and rich tourism resources. In 2017, China's domestic market continued to grow at a high speed. The number of domestic tourist arrivals reached 5 billion 1 million, up $12.8 \%$ over the same period of the previous year. The domestic tourism revenue was 4 trillion and 570 billion yuan, up $15.9 \%$ over the same period of the previous year. China's entry and exit tourism market has maintained a steady growth. The total number of inbound and outbound tourism has reached 270 million people, up $3.7 \%$ compared with the previous year, and international tourism revenue reached 123 billion 400 million US dollars, up 2.9\% over the same period of the previous year. Among them, there were 42 million 940 thousand foreign tourists, $74.6 \%$ of the Asian tourist market, and 69 billion 500 million of foreigners, up $4.1 \%$ from the same period last year. In 2017, the number of outbound tourists in China reached 130 million 510 thousand, an increase of $7 \%$ over the same period last year. In 2017, China's per capita GDP reached $\$ 8836$. In the four provinces (China) close to Southeast Asia, the amount of tourist entry and tourist income in 2017 is shown in Table 1.

TABLE I. TOURISM INCOME AND PER CAPITA GDP OF 4 PROVINCES IN CHINA NEAR SOUTHEAST ASIA IN 2017

\begin{tabular}{|c|c|c|c|c|c|c|c|}
\hline & $\begin{array}{l}\text { Total } \\
\text { income } \\
\text { of } \\
\text { tourism } \\
/ \quad \$ 100 \\
\text { million }\end{array}$ & $\begin{array}{l}\text { Year } \\
\text {-on- } \\
\text { year } \\
\text { grow } \\
\text { th } \\
\text { rate }\end{array}$ & $\begin{array}{l}\text { Reception } \\
\text { of } \\
\text { overseas } \\
\text { tourists / } \\
\text { tens of } \\
\text { thousands }\end{array}$ & $\begin{array}{l}\text { Year- } \\
\text { on- } \\
\text { year } \\
\text { grow } \\
\text { th } \\
\text { rate }\end{array}$ & $\begin{array}{l}\text { Foreign } \\
\text { exchange } \\
\text { tourism } \\
\text { revenue / } \\
\$ 100 \\
\text { million }\end{array}$ & $\begin{array}{l}\text { Year- } \\
\text { on- } \\
\text { year } \\
\text { growt } \\
\text { h } \\
\text { rate }\end{array}$ & $\begin{array}{l}\text { GDP } \\
\text { / per } \\
\text { capit } \\
\text { al in } \\
2016\end{array}$ \\
\hline $\begin{array}{l}\text { Yunna } \\
n \\
\text { Provin } \\
\text { ce }\end{array}$ & $\begin{array}{l}1097.9 \\
1\end{array}$ & $\begin{array}{l}46.5 \\
\%\end{array}$ & 667.69 & $\begin{array}{l}11.2 \\
\%\end{array}$ & 35.50 & $\begin{array}{l}15.5 \\
\%\end{array}$ & $\begin{array}{l}498 \\
8\end{array}$ \\
\hline $\begin{array}{l}\text { Guang } \\
\text { xi } \\
\text { Provin } \\
\text { ce }\end{array}$ & 885.03 & $\begin{array}{l}33.1 \\
\%\end{array}$ & 521.44 & $6.2 \%$ & 23.96 & $\begin{array}{l}10.7 \\
\%\end{array}$ & $\begin{array}{l}603 \\
2\end{array}$ \\
\hline $\begin{array}{l}\text { Fujian } \\
\text { Provin } \\
\text { ce }\end{array}$ & 806.16 & $\begin{array}{l}29.2 \\
\%\end{array}$ & 775.41 & $\begin{array}{l}13.9 \\
\%\end{array}$ & 75.88 & $\begin{array}{l}14.5 \\
\%\end{array}$ & $\begin{array}{l}118 \\
48\end{array}$ \\
\hline $\begin{array}{l}\text { Haina } \\
n\end{array}$ & 128.78 & $\begin{array}{l}20.8 \\
\%\end{array}$ & 111.94 & $\begin{array}{l}49.5 \\
\%\end{array}$ & 6.81 & $\begin{array}{l}94.6 \\
\%\end{array}$ & $\begin{array}{l}703 \\
3\end{array}$ \\
\hline
\end{tabular}

Kampuchea is located in the Indochina Peninsula. In July 2016, Kampuchea shifted from the world's least developed countries to a medium low income country. In 2017, the per capita GDP in Kampuchea was \$1389.63. Kampuchea is a member of the association of Southeast Asian nations. Its industrial base is weak. And it pay more attention to agricultural. At present, tourism is the second pillar industry in Kampuchea.

Kampuchea has rich tourism resources. more than 2000 tourist attractions have been developed. Including the world heritage of Angkor kiln, Preah Vihear temple and three Po Lei temple. And the coastal area of the 4 coastal provinces of
Kampuchea, which was selected as the world's most beautiful beach club in 2011.In 2000, Kampuchea vigorously pursued the "open sky" policy. In 2002, Kampuchea increased its financial support for tourism, developed scenic spots, restored historic sites, and improved a number of infrastructure facilities In 2009, the tourism industry in Kampuchea promoted the development of related industries. The service industry contributed $37.7 \%$ to Cambodia GDP, far exceeding its industrial output value. Between 2009 and 2015, the growth rate of Kampuchea tourism was up to $14.1 \%$, the proportion of tourism development accounted for more than $10 \%$ of its GDP, and the contribution rate of GDP in the related industries driven by tourism was close to $40 \%$, which was one of the countries with the highest percentage of GDP in the tourism industry in Asia.

In 2012, there were 334 thousand Chinese tourists to Kampuchea and 1 million 210 thousand Chinese tourists to Kampuchea in 2017, with an average annual growth rate of nearly 30\% (as shown in Chart 1). In 2017, the number of Chinese tourists to Cambodia Siem Reap reached 910 thousand, contributing about $\$ 450$ million in revenue. In 2017, China became the largest tourist source country in Kampuchea and the largest international aviation market in Kampuchea.

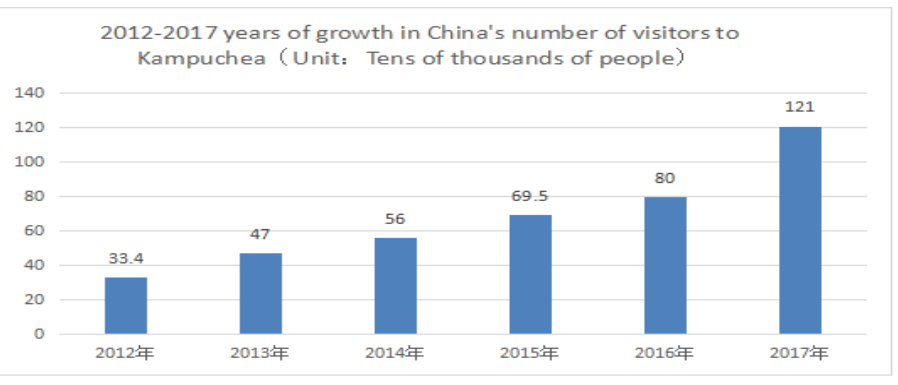

Fig. 1. 2012-2017 YEARS OF GROWTH IN CHINA'S NUMBER OF VISITORS TO KAMPUCHEA

\section{B. The Current Situation of Regional Tourism Cooperation between China and Cambodia}

\section{1) Mutual marketing cooperation between China and}

\section{Cambodia as international tourist sources}

In the development of Kampuchea's international tourism industry, China is the fastest growing tourist source country. In 2016, Kampuchea built the Sino-Cambodiann Friendship Culture Park and the Kampuchea business center in China, and actively publicize the information and policy of Kampuchea's trade and tourism. The same year in May, China international travel agency and Kampuchea cooperation, create Chinese tourism official website, and through joint marketing activities, and make contributions for the construction of One Belt One Road ".In 2017, Kampuchea plans to attract 7 million international tourists in 2020, which will attract 2 million Chinese tourists. To this end, Kampuchea Tourism Minister Tang Kun said Kampuchea will launch a "ready for China" strategy, which is fully prepared to attract Chinese tourists and serve Chinese tourists. In July 2017, the Chinese tourism delegation held a "beautiful China" Tourism Promotion Conference in Phnom Penh, capital of Kampuchea, to build the 
overall image of "beautiful China" and promote China's tourism resources and products.

2) Cooperation between China cambodia regional tourism summit forum

Since the establishment of a comprehensive strategic partnership between China and Cambodia, a series of cooperation has been carried out. In January 2015, the Ministry of tourism of Kampuchea and China National Tourism Group signed the strategic cooperation agreement on tourism industry. In May 2017, China and Cambodia held a forum on business tourism cooperation in Beijing, and signed a plan for the implementation of the memorandum of understanding on tourism cooperation between the People's Republic of China National Tourism Administration and the Kingdom of Cambodia Tourism Ministry (2017-2020).In the same year, China and Cambodia jointly held the Sino-Cambodiann tourism Summit Forum to further strengthen pragmatic cooperation in tourism between the two countries.

\section{The CONNOTATION OF SYMBIOSIS THEORY}

The earliest phenomenon of symbiosis was proposed by the German biologist, Berri (Anton de Bary), that "different species live together according to a certain material connection" ${ }^{[4]}$.Yuan Chunqing [1] introduced symbiosis theory into the field of social economic research.

In the concept of symbiosis, there are three elements including symbiotic unit, symbiotic mode and symbiotic environment. The symbiotic unit is the basic energy production and exchange unit that forms the symbiotic pattern or the symbiotic relationship. It is the basic material condition for the formation of symbionts. For example, the tourism industry in China or Kampuchea is a symbiotic unit [5].The mode of symbiosis refers to the mode of interaction between the symbiotic units or the ways of combining each other. According to the behavior mode, it can be divided into four stages: parasitism, symbiosis, asymmetric mtualistic symbiosis and symmetrically mutualistic symbiosis. According to the organizational model, it can be divided into four stages: point symbiosis, intermittent symbiosis, continuous symbiosis and integrated symbiosis. These four stages correspond to the low stage, evolution stage, development stage and advanced stage of symbiotic development respectively. Symbiotic environment refers to the external conditions of symbiotic mode. The medium of interaction between the three elements of symbiosis is also called the symbiotic interface, which is the carrier of material, information and ability transmission among the symbiotic units, which has a very important influence on the formation of symbiotic relations and the balanced development of the symbiotic system.

In the symbiotic theory, there are three kinds of symbiotic mechanisms that determine the mode of interaction and the direction of evolution between the symbiotic units, namely, the environment induction mechanism, the symbiotic dynamic mechanism and the symbiotic damping mechanism. The symbiotic dynamic mechanism mainly refers to the mutual promotion and mutual restriction between the symbiotic units, and the symbiotic dynamic mechanism can promote the evolution and development of the symbiotic units or symbiosis bodies. The symbiotic damping mechanism is due to the differences in nature, spatial distance and symbiotic interface between different symbiotic units.

\section{AN ANALYSIS OF THE SYMBIOTIC MECHANISM OF REGIONAL TOURISM COOPERATION BETWEEN CHINA AND CAMBODIA}

Among the three elements of symbiosis theory, the most important is symbiotic mode. According to the theory of symbiosis, the mode of symbiosis between China and Cambodia is changed from symbiosis to asymmetrical symbiosis, which is determined by the national conditions and actual development of the two sides. From the symbiotic organizational model, the Chinese and Cambodia are changing from the evolutionary stage to the development stage now. From the practical point of view, the Chinese and Cambodia are in a state of intermittent symbiosis, and there is a long way to go from the ideal mode of integration and symbiosis. Therefore, the Chinese and Cambodia should promote the symbiotic mode of symbiosis to the symmetrically mutualistic symbiosis stage and promote the transformation of the symbiotic organization model to the Integrated Symbiosis under the continuous improvement of the symbiotic pattern [7]

\section{A. Analysis of Environment Induction Mechanism}

- China and Cambodia have profound traditional friendship and frequent exchanges between the two sides. Geographically, China and Kampuchea are separated from Laos. In terms of religious belief, there are many Buddhist believers in China and Cambodia. In terms of diplomacy, the leaders of China and Cambodia have established good relations since the Bandung Conference. In July 1958, China and Kampuchea formally established diplomatic relations. In 2006, China and Cambodia set up a comprehensive partnership. In 2010, China and Cambodia established a comprehensive strategic partnership of cooperation. In recent years, China and Cambodia have exchanged frequent exchanges in the areas of economy, trade, infrastructure, culture and education, creating a good environment for regional tourism cooperation between the two sides.

- The political situation in China and Kampuchea is stable and the economy continues to develop at a high speed. Since China's reform and opening up, economic development has entered a stage of rapid development, with an average annual growth rate of 9.5\%.From 1978 to 2017, China reduced the number of poor people by about 740 million, and China's comprehensive strength continued to rise. In 2017, China became the world's largest trading power and contributed more than $30 \%$ to world economic growth. As the largest developing country in the world, China is also actively helping Asian African countries. In 2015, Chinese proposed "One Belt One Road" strategy and build infrastructure investment banking in Asia, has been great recognition and support of the international community. Kampuchea is actively cooperating with China, and Kampuchea's "four corners strategy" is also actively 
linked with China. In 2017, Cambodia held a forum business tourism cooperation, actively implement the "One Belt One Road" initiative. Kampuchea's domestic political stability, economic growth rate reached $7 \%$, Kampuchea is China "One Belt One Road" primary partners and beneficiaries.

- Regional tourism economic integration development. The development of the world economy has strengthened regional cooperation, especially regional tourism cooperation. China and Kampuchea participate in cooperation with WTO, CAFTA, LAN Mekong regional Cooperation (a new subregional cooperation platform was sponsored and jointly built by 6 countries such as China and Kampuchea)、China "One Belt One Road" strategy etc. The inevitable trend of tourism development in regional cooperation.

\section{B. Analysis of the Mechanism of Symbiotic Dynamics}

- China's promoting effect on Kampuchea's tourism development. In terms of tourist sources, China is the largest source of tourists for international tourism in Kampuchea. From 2012 to 2017, the average annual growth rate of Chinese tourists to Kampuchea was nearly $30 \%$.The Kampuchea government expects to attract 7 million international tourists by 2020 , of which Chinese tourists are expected to attract 2 million. In terms of tourism talents, China and Cambodia have frequent exchanges. In 2016, the two sides exchanged nearly one million people. During the Sino-Cambodiann business tourism forum, the two sides reached consensus on talent training and management experience sharing. China has helped Kampuchea develop its tourism development plan and set up a "Sino-Cambodiann tourism talents exchange project". In the restoration of tourism heritage sites, China sent experts and scholars spend 6 years to help Kampuchea repair Chau Say Tevoda of Angkor. China uses satellites to protect the world heritage and helps Kampuchea install virtual satellite receiving stations. As for tourism and transportation, as of May 2015, China has built more than 20 new roads for Kampuchea, with a total length of about 2669 kilometers, accounting for more than $35 \%$ of the total mileage of Kampuchea national road. In addition, China has helped Kampuchea build 7 extra large bridges. These measures provide great convenience for the development of Kampuchea's tourism industry.

- The promotion of tourism development in Kampuchea on China's tourism development. Kampuchea's current economic development level is relatively low. Tourism is the second pillar industry in Kampuchea, accounting for nearly $12 \%$ of the total GDP. And there is great potential for Sino-Cambodiann tourism cooperation. Kampuchea and China have strong complementarity in tourism, trade, infrastructure, science and technology and resources development, which attract China to invest, and China is now the largest investor in Kampuchea. In 2017, the Chinese tourism delegation went to Kampuchea to host the "beautiful China" tourism promotion conference, which attracted nearly 100 tourist agencies, airlines and media representatives from Kampuchea. With the improvement of Kampuchea's economic level, more and more Kampuchea people will travel to China. In addition, Kampuchea's unique tourism resources and customs also have a great attraction for Chinese tourists. In 2016 , Kampuchea has become the first choice for Chinese tourists to travel in Southeast Asia. Chinese proposed "One Belt One Road" strategy, can stimulate development along the country's tourism industry, will also make along the countries including Kampuchea tourism industry nurturing China tourism.

\section{Analysis of Symbiotic Damping Mechanism}

- In terms of the differences in the nature of the symbiotic units between China and Cambodia, There is a big gap between China and Kampuchea in terms of economic development and there are different stages in the development of tourism in the two countries. According to the world economic information network, in 2017, China's per capita GDP was 8582.94 dollars, and Kampuchea's per capita GDP was US \$1389.63.Kampuchea's per capita GDP income is even far behind that of China's four provinces in Table 1.In addition, China and Kampuchea have different market positioning, different brand image of foreign publicity. Tourism resources endowments, abundances and ethnic customs and habits are also quite different.

- China and Cambodia are separated from Laos on land and separated by Vietnam at sea. The barrier of space distance causes a great deal of cost in terms of material, energy and information exchange. This damping effect results in the consumption of the symbiotic energy on both sides, which is unfavorable to the continued cooperation between the two sides. For example, there is less Tourism Aviation between Kampuchea and China, and the price of tour groups is relatively high Moreover, as a symbiotic relationship between China and Cambodia, China and Cambodia are prone to trade protectionism and are easily influenced by the international political and economic situation.

- The regional tourism symbiosis between China and Cambodia is far from symmetric symbiosis. At present, the symbiosis model has a large asymmetry. This asymmetry will inevitably affect the division of labor in regional tourism cooperation. It will also make certain difficulties for the adjustment and redistribution of the two sides. Whether this problem can be handled fairly or reasonably will have great influence on the cooperation enthusiasm between China and Cambodia. In addition, Kampuchea's tourism market is small and its tourism infrastructure is backward. Tourism traffic can't match the speed of its tourism development. Kampuchea's national quality is not high, the education is low, the lack of corresponding tourism talents, the legal system of tourism is not perfect, the problem of corruption in Kampuchea is serious, and the insufficient non-governmental exchanges between China and 
Kampuchea have a great influence on the symbiotic relationship between China and Cambodia.

\section{CONCLUSION}

This paper applies the symbiosis theory to analyze the tourism cooperation between China and Cambodia. Based on the actual situation of regional tourism in China and Cambodia in recent years, the following conclusions can be drawn: (1) The symbiotic relationship between China and Cambodia is of great asymmetry. From the mode of symbiotic behavior, The mode of symbiosis between China and Cambodia is in the stage of transition from partial symbiosis to asymmetric symbiosis. From the symbiotic organizational pattern, China and Cambodia are changing from evolution stage to development stage. In terms of actual development, China and Cambodia are in a state of intermittent symbiosis, while the ideal mode of Sino-Cambodiann symbiosis is the mode of Integrated Symbiosis. (2)With the deepening of SinoCambodiann regional tourism cooperation, the SinoCambodiann symbiosis model will continue to evolve and develop, and the degree of dependence between the two sides will be deepened, but to avoid serious imbalance in the SinoCambodiann symbiotic relationship, whether the symbiotic relationship between the two sides will be seriously unbalanced depends on symbiotic asymmetry. Furthermore, in the process of evolution and development of the mode of symbiotic symmetrically mutualistic symbiosis between China and Cambodia, the relationship between the environmental induction mechanism, the symbiotic dynamic mechanism and the symbiotic damping mechanism should be properly handled. The first two forces play a catalytic role, and the third force acts as a drag force. In addition, with the development of the Sino-Cambodiann symbiotic relationship, we should properly handle the relationship between the new interest adjustment and redistribution between the two countries and Cambodia, which plays a vital role in the sustainable development of the Sino-Cambodiann regional tourism cooperation and the development of the Sino-Cambodiann symbiotic relationship.

\section{ACKNOWLEDGMENT}

Thanks for the tutor Liu Yun's support and guidance. Thank you for the academic discussion platform provided by this International Conference. Thank you for the people who participated in this meeting.

\section{REFERENCES}

[1] Yuan Chunqing. Symbiosis Theory--On small economy[M].Beijing: Economic Science Press, 1998.

[2] Zhang Jianhua, Yu Jianhui, Hong Yuancheng.Research on tourism cooperation mechanism between Fujian and Taiwan based on Symbiosis Theory[J].Journal of Fujian Agriculture And Forestry University (PHILOSOPHY AND SOCIAL SCIENCES),2008,11(1):58-61.

[3] Tang Zhongxia, Ma Yaofeng, Xiao Jingyi.Study on regional cooperation of inbound tourism in Qinghai Tibet Based on Symbiosis Theory[J].Ethnic studies in Qinghai, 2012, 1.

[4] Huang Xiaoyong, Chen Yunping.Literature review on inclusive growth of regional economy based on Symbiosis Theory[J].East china economic management, 2012,07.

[5] Zhang Linan. Research on Stability of Inter-firm Cooperation Relations In Strategic Networks with Symbiotic Theory[D].Finance and Economics University Of Tianjin,2013,5.

[6] Cheng Datao. Study on the Basis of the Intergrowth Theory of the Enterprise Clusters Organization[D].Zhejiang University,2003,11.

[7] Xiao Yang.Research on competitive innovation mode of regiona tourism cooperation in Southwest Guangxi -- Based on Symbiosis Theory[J].Consumer guide and consumer market,2009,3

[8] Huang Min.Research on the Stakeholders Management Based on the Symbiosis Theory- - Take the Heshun Ancient Town in Tengchong as a Case[D].Yunnan University,2011,6.

[9] Li Qiang, WeiWei.Review on the application of Symbiosis Theory in urban agglomeration research[D].Journal of Yulin University,2011,1(1). 